\title{
A Markov Switching SVAR analysis on the relationship between exchange rate changes and stock returns in China
}

\author{
Juan Carlos Cuestas \\ Department of Economics and Finance, Tallinn University of Technology \\ Department of Economics, Jaume I University \\ Economics and Research Department, Eesti Pank \\ Bo Tang $\dagger$ \\ Big Data Department, Weichai Power Co., Ltd \\ Department of Economics, University of Sheffield
}

\begin{abstract}
This study investigates the spillover effects between exchange rate changes and stock returns in China. We find that no significant interconnections exist between stock returns and exchange rates changes. Although the conventional structural VAR (SVAR) approach fails to examine the contemporaneous effects, the Markov switching SVAR model captures the volatile structure of the Chinese financial market. The regime-switching estimates indicate that volatile structure tends to be significant during two financial crisis periods. Notwithstanding the fact that exchange rate changes cannot Granger-cause stock returns in the long run, its contemporaneous spillover effects on stock returns are found to be statistically significant.
\end{abstract}

JEL Codes: C32, C580, F31

Keywords: exchange rate changes, stock returns, Markov switching SVAR.

\section{Acknowledgements}

We gratefully acknowledge Arne Risa Hole, Gurleen Popli, Karl Taylor and the conference participants at the York-MMF-Bank of England Macro PhD workshop 2015 (York, UK), the XVII Applied Economics Meeting (Gran Canaria, Spain), the 3rd White Rose DTC conference (Sheffield, UK) and the Sheffield economics $\mathrm{PhD}$ annual conference for their insightful comments and suggestions. We are very grateful to Margarita Zabelina and Tao Zha for their kind help on the technique issues of this study. Comments from two anonymous referees are gratefully acknowledged. The usual disclaimer applies.

Emails: cuestas@uji.es (J.C.Cuestas), bo.tang@ hotmail.com (B.Tang), Correspondence: Department of Economics, University of Sheffield, 9 Mappin Street, Sheffield, S1 4DT, UK. Tel: + 44114222 3421, Fax: + 441142223458. 


\section{Introduction}

The classical economic theory pinpoints that there are spillover effects between the currency market and the stock market performance. There are two schools of research in this sense. The first school is concerned about the current account balance (or trade balance) channel, which was proposed by Dornbusch and Fischer (1980). This approach has been dominant in the "flow-oriented" exchange rate models. The supporters of these models claim that the change in the exchange rate has an impact on international competitiveness and thereby affecting growth and real income. Stock prices respond to exchange rate changes since a firm's current value of future cash flows is expressed and interpreted by stock prices under efficiency of markets. ${ }^{1}$ The second group is the "stock-oriented" exchange rate models (Frankel, 1983), which assume that innovations in stock markets influence aggregate demand through the wealth channel and liquidity effects, and therefore have an impact on the money demand (Gavin, 1989). These theories seem to suggest that spillover effects exist between the foreign exchange market and the stock market.

This study aims to shed light on the spillover effects between exchange rate changes and stock returns in China, as the Chinese currency is becoming flexible and China's stock market has undertaken important reforms. The spillovers between the two markets are of topical importance due to the increasing connections between China and the global economy. The Chinese currency system is believed to protect the Chinese economy from external shocks to a greater extent, which also helps to stabilize the regional economy (Ma and McCauley, 2011; Hung and Ma, 2017). The international community is increasingly pressing the Chinese authorities to appreciate the Reminbi (RMB, the Chinese currency) since it has caused large US trade deficits (Woo, 2008). In response to those

\footnotetext{
${ }^{1}$ The fundamental theory of value suggests that the value for a financial asset at any point in time is equal to the present value of future cash flows. Empirical evidence can also be found on the study of Shanghai stock prices (Chow et al., 1999).
} 
pressures, China has to make appropriate changes to the currency policy. The RMB daily trading band has been widened from $0.3 \%$ (1994) to $0.5 \%$ (2007), $1 \%$ (2012), and $2 \%(2014){ }^{2}$ These changes gradually make the market play a big role in determining the RMB exchange rate. Furthermore, the Chinese government is accelerating the pace of RMB internationalisation, which may exhibit a significant impact on stock market performance. While on the Chinese stock market, the launch of the Shanghai-Hong Kong Stock Connect and the Shenzhen-Hong Kong Connect effectively promotes the capital mobility but exposes the Chinese stocks to external shocks like the movement in the exchange rate. In conjunction with the "flow-oriented" and "stock-oriented" theories, the spillover effects between exchange rates and stock prices under the circumstance of an intermediate exchange rate policy in China is of interest to academics and also of importance to investors.

There have been an increasing number of studies on the interactions between exchange rates and stock prices. Ketty (2010) reveals that there exits short run relationship between stock prices and exchange rates and there is no long run correlation between the two variables. Applying both the multivariate GARCH model and the Diebold Yilmaz model, Kumar (2013) indicates the existence of bi-directional spillovers between stock and foreign exchange markets in the IBSA countries. Interestingly, he also finds that the stock markets play a relatively more important role than foreign exchange markets in the first and second moment interactions and spillovers. This is evidenced in the case of the euro-dollar rate and two composite European stock market indices (Kollias and Paleologou, 2012), as well as the case of UK and Norway( Kollias and Siriopoulos, 2016). Regarding the Chinese financial market, the main findings of the existing studies reveal that foreign capital share returns in the Chinese stock market are not entirely segmented from global financial conditions (Bailey, 1994); there exists bidirectional volatility spillovers between stock prices and exchange rates (Zhao, 2010; Cuestas et al., 2018); asymmetric causal relationship running from exchange rates to A-

${ }^{2}$ See the RMB history via the link: www.thechinastory.org /lexicon/renminbi/. 
share returns (Nieh and Yau, 2010). The disparities among these studies could be the application of different samples and econometric strategies. However, the Chinese stock market is constituted by RMB ordinary shares (known as A shares) and foreign capital shares (known as B shares). The evidence from both the A shares and B shares is commonly ignored in the previous literature. Moreover, the Hong Kong stock market is increasingly linked to the mainland stock market (Poon and Fung, 2000; Li et al., 2006; Johansson and Ljungwall, 2009). However, these studies seem to have different arguments in the short run and long run dynamic effects. The investigation of the nexus between stock markets and foreign exchange markets in China should take all these indicators into account. Added to that, the gradual loosening of restrictions on the RMB exchange rate might have made the Chinese financial market more vulnerable than before, particularly during financial crises. Therefore, it would be of interest to look at spillover effects in different sample periods in the Chinese financial market, which is expected to have important implications for both academic and practical professionals.

Motivated from the two schools of economic theories and the widely discussed spillovers between stock prices and exchange rates, this paper is interested in the examination of the spillover effects of stock markets and financial markets in China by applying popular econometric models indicated in the literature, as well as the exploration of the dynamics both in the short run and the long run. Different from previous studies on the Chinese financial market, this study investigates the causality between exchange rate changes and stock returns using a multivariate vector autoregression (VAR) approach. The test of causal relationships is based on the standard Wald tests. Since the VAR model is unrestricted and cannot examine structural innovations, we introduce the conventional structural VAR (SVAR) to explore the contemporaneous effects between exchange rate changes and stock returns. Nevertheless, the SVAR model is inadequate to interpret some of the shocks of interest due to the inherent weaknesses, such as the normality assumption and model identification techniques. 
Therefore, we apply the Markov switching SVAR model to investigate the spillover effects, with which both the mean and volatility spillovers could be examined.

This study contributes to the literature in three ways. First, the spillover effects between exchange rate changes and stock returns are investigated using a Markov switching SVAR model that allows both the mean and variance to switch. The evidence suggests that currency movements exhibit little impact on stock returns, but returns of market portfolio have a significant impact on exchange rate changes. Second, the examination of spillovers in the Chinese financial market has taken into consideration the division of RMB ordinary shares (A shares) and foreign capital shares (B shares), which are commonly ignored in the literature. The empirical evidence shows that there is no long run correlation between stock markets and foreign exchange markets. Foreign capital shares listed in the Shanghai market tend to have spillover effects on the returns of Shenzhen B shares. Changes in the USD show significant impact on the Hong Kong foreign exchange market. This could be explained by two reasons: (1) the Chinese authorities implement a managed floating currency system, and the currency daily trading band is restricted with $2 \%$, which gives investors an expected range for currency exposures, they could easily offset the currency risk using different types of hedging strategies, such as future and option; (2) the Chinese stock market is immature and the very weakform efficiency market might reflect the case in China. Finally, we find that spillover effects appear to be significant during financial crises.

The remaining parts of this paper are organised as follows. The empirical literature on the interactions between exchange rates and stock prices is discussed in section 2. Section 3 presents econometric models and the technical inferences. Section 4 gives the data and preliminary statistics. Empirical results are shown in section 5 and the last section concludes. 


\section{Exchange Rates Changes and Stock Returns: the Empirical Literature}

This section briefly reviews the literature on the relationship between exchange rates and stock prices according to the classification of different economies: emerging economies, developed economies and the interactions between emerging economies and developed economies. ${ }^{3}$ China is widely considered to be an emerging economy due to its continuous growth since 1978, which has been receiving much attention from the international community.

With the fast growing of emerging economies and the increasing openness of the world economy, the dynamic linkages between exchange rate changes and stock returns in emerging markets have been subject of an increasing literature (Sensory and Tabak, 2016; Cuestas et.al., 2018; Enders et. al., 2018). Based on the Markov regime-switching framework, the empirical results show some discrepancies among different emerging markets: Chkili and Nguyen (2013) suggest that exchange rate changes have no effects on stock returns, but stock returns have a significant impact on exchange rate changes in BRICS countries except for South Africa; but Tovar-Silos and Shamim (2013) find a positive correlation between exchange rates and stock prices in South Africa; Walid et al. (2011) indicate that stock prices asymmetrically respond to currency movements in four emerging economies (Hong Kong, Singapore, Malaysia and Mexico), and exchange rate movements affect transition probabilities across regimes. It is noticeable that the number of literature on the spillover effects between exchange rates and stock prices in Asian emerging economies surged in the past two decades, due to their increasing influences in the Asia-Pacific region and their connections with the global economy, especially after the 1997 Asian financial crisis (Fang, 2002; Granger et al., 2000;

\footnotetext{
${ }^{3}$ This study classifies emerging economies referring to the classifications from the International Monetary Fund (IMF)(July 2012) and the Emerging Market Global Players (EMGP) project at the Columbia University (April 2013), as well as the list tracked by The Economist.
} 
Lin, 2012). Caporale et.al.,(2017) also find the evidence that capital controls could be an effective tool for stabilizing the foreign exchange market in the Markov Switching model.

Although stock markets in developed countries are assumed to have a sophisticated regime and may withstand the shock from currency movements, a number of studies find the existence of spillovers between exchange rates and stock prices, for example, Dominguez (2001) indicates that exchange rate movements have a significant impact on stock prices at both the firm and sectoral levels in industrial countries. For the US, (Bahmani-Oskooee and Sohrabian, 1992) find that the linkage between exchange rates and stock prices (S\&P 500) is bidirectional in the short run. However, Kim (2003) and Choi et al. (1992) claim that the relationship between the two markets are unidirectional and negative, which runs from exchange rates to stock prices. As for G-7 countries, Nieh and Lee (2002) indicate that there is no long run relationship but the one-day correlation exists in the financial markets of Germany, Canada and UK. ${ }^{4}$ Interestingly, Ma and Kao (1990) suggest that currency appreciations have a negative impact on the domestic market in an export-dominant economy since it weakens the competitiveness of export markets, while appreciated currencies reduce import costs and have positive effects on the domestic stock market if it is an import-dominated economy.

The existing literature suggests that spillover effects might spread from advanced financial markets to emerging markets (Coudert et al., 2011; Chow et al., 2011). The crisis happening in one emerging country may also spread to its neighboring emerging economies, as financial market trends to be more volatile during financial crisis (Boako and Algidede, 2017). However, this underlying interaction between stock markets and foreign exchange markets might change (Sensoy and Tabak, 2016). Phylaktis and Ravazzolo (2005) point out that the positive correlations between exchange rates

\footnotetext{
${ }^{4}$ The one-day correlation means that the currency depreciation will drag down or stimulate stock returns on the following day.
} 
and stock prices in the Pacific Basin economies are linked through the channel of the US stock market, but the shocks from financial crisis to the long run interactions among these markets are temporal. Nevertheless, empirical evidence shows that currency shocks are not economically important for investors (Griffin and Stulz, 2001), since exchange rate shocks are exogenous to stock returns, which are mainly determined in the domestic market (Grammig et al., 2005). Possible solutions of reduce currency risks are the application of hedging stractities ( Wang and Lee, 2016; Cuestas et al., 2018)

\section{Econometric Modelling}

\subsection{Hypothesis}

Since the Chinese authorities implement a managed floating currency policy, the daily trading band is restricted at a narrow band, i.e., $2 \%$, the foreign exchange market therefore has expected and limited impact on stock markets. Financial institutes could flexibly apply hedging strategies to offset currency exposures at ease. The hypothesis here in this study is proposed in the following:

H0: There are no spillover effects running either from foreign exchange markets to stock markets, or from stock markets to foreign exchange market.

H1: There are limited or some spillovers existing in the Chinese financial market.

A majority of investors bear in mind this hypothesis as they believe this reflects the general impression of the common people when they talk about the Chinese financial market. Based on the hypothesis, VAR models are introduced to examine the spillovers between the foreign exchange market and the stock market.

\subsection{Theoretical Model and Conventional Structural VAR Model}


The existing studies find that the spillover effects between exchange rate changes and stock returns is either bidirectional $\left(\mathrm{SR}_{\mathrm{t}}^{\mathrm{j}} \Leftrightarrow \mathrm{ER}_{\mathrm{t}}^{\mathrm{i}}\right)^{5}$ (Pan et al., 2007; Rjoub, 2012), or unidirectional $\left(\mathrm{SR}_{\mathrm{t}}^{\mathrm{j}} \Leftarrow \mathrm{ER}_{\mathrm{t}}^{\mathrm{i}}\right.$ or $\left.\mathrm{SR}_{\mathrm{t}}^{\mathrm{j}} \Rightarrow \mathrm{ER}_{\mathrm{t}}^{\mathrm{i}}\right)(\mathrm{Kim}, 2003$; Lin, 2012), or uncorrelated in the long run equilibrium (Tabak, 2006) and in the short run (Nieh and Yau, 2010), that is $\mathrm{SR}_{\mathrm{t}}^{\mathrm{j}} \Leftrightarrow \mathrm{ER}_{\mathrm{t}}^{\mathrm{i}}$. The conventional econometric method for examining the causal relationship between exchange rate movements and stock returns is the Granger causality test (Pan et al., 2007), which is based on the bivariate VAR (BVAR) model:

$$
\begin{aligned}
& \mathrm{ER}_{\mathrm{t}}=\sum_{j=1}^{m} \alpha_{\mathrm{j}} \mathrm{ER}_{\mathrm{t}-\mathrm{j}}+\sum_{j=1}^{n} \beta_{j} \mathrm{SR}_{\mathrm{t}-\mathrm{j}}+\varepsilon_{\mathrm{t}} \\
& \mathrm{SR}_{\mathrm{t}}=\sum_{\mathrm{j}=1}^{\mathrm{m}} \gamma_{\mathrm{j}} \mathrm{ER}_{\mathrm{t}-\mathrm{j}}+\sum_{\mathrm{i}=1}^{\mathrm{n}} \eta_{\mathrm{j}} \mathrm{SR}_{\mathrm{t}-\mathrm{j}}+\mu_{\mathrm{t}}
\end{aligned}
$$

When $\beta_{\mathrm{j}}=0$, stock returns fail to Grange-cause exchange rate changes. Exchange rate changes cannot Grange-cause stock returns only if $\gamma_{j}=0$. This study assumes that foreign capital shares and RMB ordinary shares in the Chinese stock market receive different spillover effects from foreign exchange markets, therefore the reduced form of the $k$-dimensional vector autoregressive (VAR) model with $p$-th lags is proposed (Lütkepohl, 2005):

$$
y_{t}=D d_{t}+A_{1} y_{t-1}+\cdots+A_{p} y_{t-p}+u_{t}
$$

Where $\mathrm{y}_{\mathrm{t}}=\left(\mathrm{y}_{1 \mathrm{t}}, \ldots, \mathrm{y}_{\mathrm{kt}}\right)^{\prime}$ is a $k \times 1$ dimensional vector. $D$ is the coefficient matrix of the deterministic components $d_{t} . A_{i}$ are $k \times k$ coefficient matrices for $i=1, \ldots, p$, and $u$ is a $k$-element vector of error terms. The causality test is based on the Wald tests of the lagged terms (shocks) in matrices $A_{i}$. However, the standard VAR approach for testing the causality is an unrestricted model, which cannot explore the contemporaneous effects between exchange rate changes and stock returns. Further stronger assumptions that are more directly associated with certain theories can be imposed

\footnotetext{
${ }^{5}$ Here $S R$ and $E R$ designate stock returns and exchange rate changes, respectively.
} 
on the structural VAR (SVAR) model (Mehrotra, 2007; Lanne et al., 2010). To specify the SVAR, we re-write equation (3) and incorporate additional contemporaneous endogenous shocks and the simple error structure into each equation. The typical A-B model form of the SVAR is expressed as:

$$
A y_{t}=D^{s} d_{t}+A_{1}^{s} y_{t-1}+\cdots+A_{p}^{s} y_{t-p}+B \varepsilon_{t}
$$

Where $\mathrm{y}_{\mathrm{t}}$ is a $k$-dimensional vector of endogenous variables. A ( $\mathrm{A}$ is full rank), $\mathrm{D}^{\mathrm{s}}, \mathrm{A}_{\mathrm{i}}^{\mathrm{s}}(\mathrm{i}=1, \ldots, \mathrm{p}$ ) and $\mathrm{B}$ are $k \times k$ structural form argument matrices. $\varepsilon_{\mathrm{t}}$ is a $k$-dimensional identity covariance matrix vector of structural innovations, $\varepsilon_{\mathrm{t}} \sim\left(0, \mathrm{I}_{\mathrm{K}}\right)$. The matrix can be normalized as $\sum \varepsilon=\mathrm{I}_{\mathrm{K}}$. When $\mathrm{A}=\mathrm{I}_{\mathrm{K}}$ and $\mathrm{B}=\mathrm{I}_{\mathrm{K}}$, it is called as $B$-model and $A$-model, respectively. According to equation (3) and (4), $\mathrm{u}_{\mathrm{t}}=\mathrm{A}^{-1} \mathrm{~B} \varepsilon_{\mathrm{t}}$, and $\sum \mathrm{u}=\mathrm{A}^{-1} \mathrm{BB}^{\prime} \mathrm{A}^{-1^{\prime}} \cdot \sum \mathrm{u}$ has $k(k+1) / 2$ equations. Since both $A$ and $B$ have $k^{2}$

elements, thus a minimum of $2 \mathrm{k}^{2}-\frac{1}{2} \mathrm{k}(\mathrm{k}+1)$ restrictions are required to identify matrices $A$ and $B$. Estimating the SVAR is to minimise the log likelihood function:

$$
\ln L_{c}(A, B)=-\frac{K T}{2} \ln (2 \pi)+\frac{T}{2} \ln |A|^{2}-\frac{T}{2} \ln |B|^{2}-\frac{T}{2} \operatorname{tr}\left(A^{\prime} B^{\prime-1} B^{-1} A \tilde{\Sigma}_{u}\right)
$$

Model overidentification can be examined applying the Likelihood Ratio (LR) test: $L R=$ $\left.T\left(\log \operatorname{det}\left(\tilde{\Sigma}_{u}^{r}\right)-\log \operatorname{det} \widetilde{(\Sigma}\right)\right)$. SVAR model has to be identified by imposing short run or long run restrictions on parameters. However, the statistical validity of these restrictions cannot be examined and the identification technique is usually inadequate to interpret some of the shocks of interest. In reality, the normality hypothesis is not supported by any theories and it is usually not necessary for the asymptotic inference. Fortunately, the existence of various error covariance matrices across states in structural innovations can be captured by the Markov switching (MS) mechanism, which could also graphically present the distress and tranquil periods of an economy in the smoothed state probabilities.(Sims et al., 2008; Lanne et al., 2010; Caporale et. al., 2017).

\subsection{SVAR Model with Different Volatility Regimes}


In the MS-SVAR model, the distribution of the error term $u_{t}$ is assumed to depend on a Markov process $s_{t}$ (Lanne and Lütkepohl, 2010; Lanne et al., 2010; Netsunajev, 2013). Where $s_{t}$ is a discrete state process with $t=(0, \pm 1, \pm 2, \ldots \pm M)$ and the transition probabilities are: $\mathrm{p}_{\mathrm{ij}}=\operatorname{Pr}\left(\mathrm{s}_{\mathrm{t}}=\mathrm{j} \mid \mathrm{s}_{\mathrm{t}-1}=\mathrm{i}\right.$, $i, j=1, \ldots, M$.

$$
\mathrm{u}_{\mathrm{t}} \mid \mathrm{s}_{\mathrm{t}} \sim \mathrm{N}\left(0, \Sigma_{\mathrm{st}}\right)
$$

Generally, the distribution of $u_{t}$ conditional on $s_{t}$ is assumed to be normal. This is just for the convenience of setting up the likelihood function. Pseudo maximum likelihood (ML) estimator is used when the conditional normality of $u_{t} \mid s_{t}$ does not hold. Therefore the normality assumption is not necessary for identifying these shocks. The covariance $\Sigma_{\text {st }}$ in equation (6) varies across regimes and it is consistent with the statistical properties. Taking two states as an example $(M=2), p=$ $\left[\begin{array}{ll}\mathrm{p}_{00} & \mathrm{p}_{01} \\ \mathrm{p}_{10} & \mathrm{p}_{11}\end{array}\right] . \quad \mathrm{P}=\left(\mathrm{s}_{\mathrm{t}}=0 \mid \mathrm{s}_{\mathrm{t}-1}=0\right)=\mathrm{p}_{00} \quad, \quad$ so $\quad \mathrm{P}=\left(\mathrm{s}_{\mathrm{t}}=1 \mid \mathrm{s}_{\mathrm{t}-1}=0\right)=1-\mathrm{p}_{00} \quad . \quad \mathrm{P}=$ $\left(s_{t}=1 \mid s_{t-1}=1\right)=p_{11}$, then $P=\left(s_{t}=0 \mid s_{t-1}=1\right)=1-p_{11}$. The unconditional probabilities: $\mathrm{p}\left(\mathrm{s}_{\mathrm{t}}=0\right)=\left(1-\mathrm{p}_{11}\right) /\left(2-\mathrm{p}_{11-} \mathrm{p}_{22}\right)$ and $\mathrm{p}\left(\mathrm{s}_{\mathrm{t}}=1\right)=1-\mathrm{p}\left(\mathrm{s}_{\mathrm{t}}=0\right)$. Regarding the switching states, the MS structure is a mix of normal disturbance terms, $\mathrm{u}_{\mathrm{t}}=\left\{\begin{array}{cc}\mathrm{N}\left(0, \Sigma_{1}\right) & \mathrm{p}_{11} \\ \ldots & \ldots . \\ \mathrm{N}\left(0, \Sigma_{\mathrm{m}}\right) & \mathrm{p}_{\mathrm{mm}}\end{array}\right.$. The structural shock identification for the MS model is based on the assumption that only the variances are orthogonal across states and it will not affect impulse response functions. In addition, temporary shocks will not change across all sample periods. Since the error term $\left(\varepsilon_{\mathrm{t}}=\mathrm{B}_{\mathrm{t}}^{-1}\right)$ determines the structural shocks, any restrictions on the conventional SVAR inferred from theory models are testable and over-identified.

We can then rewrite the SVAR equation (4) as $A_{0} y_{t-i}=F_{t-i}+\varepsilon_{t}$, where $F_{i}$ is coefficient matrices and $\mathrm{x}_{\mathrm{t}-\mathrm{i}}$ is a vector of lagged variables. Sims et al. (2008) introduce the Markov switching SVAR in a Bayesian form, but all matrices can be state-dependent: 


$$
A\left(s_{t}\right) y_{t-i}=F\left(s_{t}\right) x_{t-i}+\Xi^{-1}\left(s_{t}\right) \varepsilon_{t}
$$

Where $\Xi$ is a diagonal matrix and $s_{t}$ is defined as $m$-states Markov process with transition matrix $\mathrm{Q}=\mathrm{q}_{\mathrm{i}, \mathrm{j}}$ (transition probabilities). Equation (7) allows all the matrices to switch in a Markov process. The other two types of MS processes are the coefficients-switching and variances-switching, respectively.

$$
\begin{gathered}
\Xi\left(s_{t}\right) A\left(s_{t}\right) y_{t-i}=\Xi\left(s_{t}\right) F\left(s_{t}\right) x_{t-i}+\varepsilon_{t} \\
A y_{t-i}=F x_{t-i}+\Xi^{-1}\left(s_{t}\right) \varepsilon_{t}
\end{gathered}
$$

The maximum likelihood (ML) estimation is commonly used in estimating the MS-SVAR. The pseudo ML estimation is applied when the conditional normality distribution does not hold. The log likelihood function for a $M$-state MS-SVAR model: $\log \mathrm{L}_{\mathrm{t}}=\sum_{\mathrm{t}=1}^{\mathrm{T}} \operatorname{logf}\left(\mathrm{y}_{\mathrm{t}} \mid \mathrm{Y}_{\mathrm{t}-1}\right)$, where $\mathrm{f}\left(\mathrm{y}_{\mathrm{t}} \mid \mathrm{Y}_{\mathrm{t}-1}\right)=$ $\sum_{\mathrm{i}=0}^{\mathrm{M}} \operatorname{Pr}\left(\mathrm{s}_{\mathrm{t}}=\mathrm{i} \mid \mathrm{Y}_{\mathrm{t}-1}\right) \mathrm{f}\left(\mathrm{y}_{\mathrm{t}} \mid \mathrm{s}_{\mathrm{t}}=\mathrm{i}, \mathrm{Y}_{\mathrm{t}-1}\right)$. The (pseudo) conditional likelihood function is expressed as follows:

$$
\mathrm{f}\left(\mathrm{y}_{\mathrm{t}} \mid \mathrm{s}_{\mathrm{t}}=\mathrm{i}, \mathrm{Y}_{\mathrm{t}-1}\right)=(2 \pi)^{-\frac{\mathrm{k}}{2}} \operatorname{det}\left(\Sigma_{\mathrm{i}}\right)^{-\frac{1}{2}} \exp \left(\frac{1}{2} \mathrm{u}_{\mathrm{t}}^{\prime} \Sigma_{\mathrm{i}}^{-1} \mathrm{u}_{\mathrm{t}}\right), \mathrm{i}=1, \ldots, \mathrm{M}
$$

Where $\mathrm{Y}_{\mathrm{t}-1}$ is a matrix with the past information up to time t. $\Sigma_{1}=\mathrm{BB}^{\prime}, \Sigma_{\mathrm{i}}=\mathrm{B} \Lambda_{\mathrm{i}} \mathrm{B}^{\prime}, \mathrm{i}=1, \ldots, \mathrm{M}$. The selection of state numbers really matters the Markov switching model. Considering the state changes in stock returns (or exchange rate changes), two or three states are normally selected, ${ }^{6}$ but we have to test the validity of states selection in a statistical perspective. Normally, the log likelihood statistics with Akaike Information Criteria (AIC) and Schwarz Information Criteria (SIC) are reliable approaches to determine the best MS model (Psaradakis and Spagnolo, 2006).

\section{Data and Preliminary Statistics}

\footnotetext{
${ }^{6}$ The structural innovations between stock returns and exchange rate movements can be positive, negative or no changes, so the number of states should be selected based on the information criteria.
} 
Monthly data were used in this study, spanning the period from 1994/01 to 2018/01. The monthly exchange rates of USD against RMB (USD/RMB) and HKD against RMB (HKD/RMB) were collected from the State Administration of Foreign Exchange of China. Five market indexes were obtained from the Qianlong Securities trading software, namely the Shanghai A-share Index (SHAI), the Shanghai B-share Index (SHBI), the Shenzhen A-share Index (SZAI), the Shenzhen B-share Index (SZBI) and the Hang Seng Index (HSI). SHAI and SZAI are RMB ordinary shares, which are listed in the Shanghai and Shenzhen Stock Exchanges, respectively. SHBI and SZBI are foreign stock shares, which are traded in USD and HKD, respectively ${ }^{7}$. The plots of exchange rates and stock indexes are shown in Figure 1.

\footnotetext{
${ }^{7}$ The Chinese stock market is constituted by RMB ordinary shares (known as A-share) and foreign capital shares (known as B-share). A-shares consist of the Shanghai A-share and the Shenzhen Ashare, which are listed in the Shanghai Stock Exchange (SSE) and the Shenzhen Stock Exchange (SZSE), respectively. Similarly, B-shares also have two categories: the Shanghai B-share and the Shenzhen B-share, which are traded in the US dollar (USD) and the Hong Kong Dollar (HKD), respectively. Therefore, the corresponding foreign exchange rates are the USD to RMB (USD/RMB) and the HKD to RMB (HKD/RMB). In addition, the shock from the Hong Kong stock market, specially the Hang Seng Index (HSI), is closely monitored by many investors.
} 
Figure 1: Exchange Rates and Stock Indexes
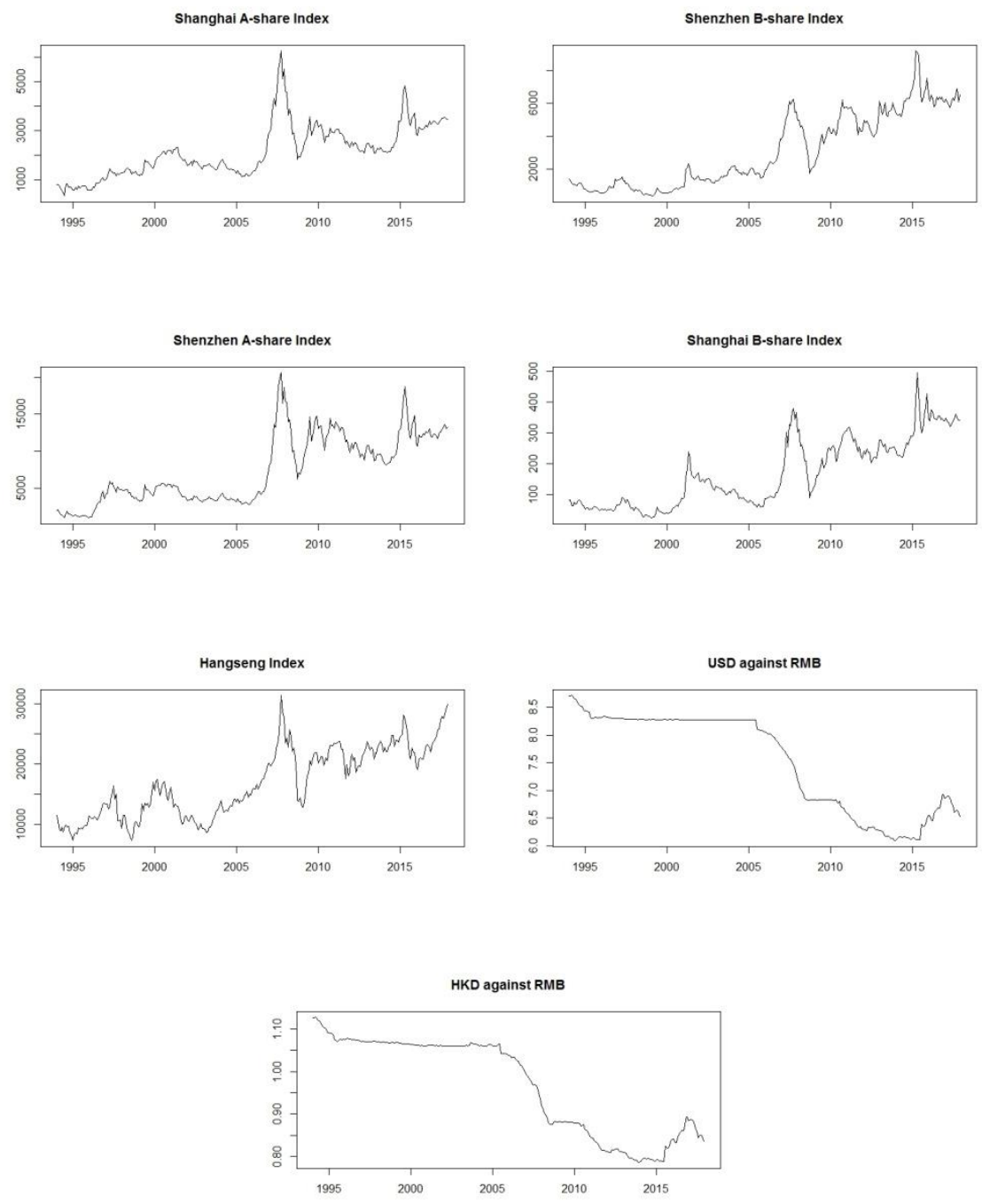

The commonly used method of calculating exchange rate changes is taking the natural logarithms of the division between two continuous closing values (Zhao, 2010; Walid et al., 2011). The changes in the exchange rate $E R_{t}^{i}$ and stock returns $S R_{t}^{j}$ in this study are calculated using the following equations:

$$
\mathrm{ER}_{\mathrm{t}}^{\mathrm{i}}=\ln \left(\frac{\mathrm{p}_{\mathrm{t}}^{\mathrm{i}}}{\mathrm{p}_{\mathrm{t}-1}^{\mathrm{i}}}\right) \quad \mathrm{SR}_{\mathrm{t}}^{\mathrm{i}}=\frac{\mathrm{q}_{\mathrm{t}}^{\mathrm{i}}-\mathrm{q}_{\mathrm{t}-1}^{\mathrm{i}}}{\mathrm{q}_{\mathrm{t}-1}^{\mathrm{i}}}
$$

Where $\mathrm{p}_{\mathrm{t}}^{\mathrm{i}}$ denotes the exchange rate (USD/RMB or HKD/RMB) at time $t . \mathrm{q}_{\mathrm{t}}^{\mathrm{i}}$ is the stock index ( $j=1$ to 5 for SHAI, SHBI, SZAI, SZBI, HSI, respectively) at time $t$. Table 1 reports summary statistics of exchange rate changes and stock returns. Since the VAR model requires 
that all variables need to be stationary, otherwise, we have to use the cointegration approach if there is a mix of integration orders. The stationarity of these series are examined by using the Augmented Dicky Fuller (ADF) unit root test (Dickey and Fuller, 1979) and the PhillipsPerron(PP) unit root test (Phillips and Perron, 1988). Table 2 reports the stationary test results. All of the statistics are significant at the $1 \%$ level, which implies that these variables are stationary in levels.

Table 1: Summary statistics of exchange rates and stock indexes

\begin{tabular}{|c|c|c|c|c|c|c|}
\hline \multicolumn{7}{|c|}{ Panel A: Descriptive statistics for exchange rate changes } \\
\hline & \multicolumn{5}{|c|}{ Mean Std.Dev Skewness Kurtosis Normality } & $\mathrm{Q}(36)$ \\
\hline USD/RMB & 0.0000 & 0.0029 & -1.141 & 1.1744 & $0.8365 * * *$ & $246.76 * * *$ \\
\hline $\mathrm{HKD} / \mathrm{RMB}$ & -0.0012 & 0.0030 & -1.082 & 0.9541 & 0.8872 & $180.12 * * *$ \\
\hline \multicolumn{7}{|c|}{ Panel B: Descriptive statistics for stock returns } \\
\hline SHAI & 0.0059 & 0.0722 & 0.0402 & -0.4516 & 0.977 & $59.347^{*}$ \\
\hline SHBI & 0.0081 & 0.0952 & 0.4424 & 0.0502 & $0.9637^{*}$ & $40.259 * * *$ \\
\hline SZAI & 0.0091 & 0.0841 & 0.2726 & -0.4693 & $0.9688 * * *$ & $83.515 * * *$ \\
\hline SZBI & 0.0066 & 0.0850 & 0.1260 & -0.4977 & $0.9772 * * *$ & $55.540 * *$ \\
\hline HSI & 0.0061 & 0.0593 & -0.0333 & -0.4927 & $0.9734 * * *$ & 28.203 \\
\hline
\end{tabular}

Notes:

1. Exchange rate changes and stock returns were calculated according to equation (11).

2. ***,** denotes the rejection of the null hypothesis at the $1 \%$ level and $5 \%$ level, respectively.

3. The normality test is a Shapiro-Wilk Normality Test.

4. Q(36) is the 36th order of Ljung-Box Q-statistics in levels.

Table 2: Stationary tests of exchange rate changes and stock returns

\begin{tabular}{cccccccc}
\hline & USD/RMB & HKD/RMB & SHAI & SHBI & \multicolumn{1}{l}{ SZAI } & SZBI & HSI \\
\hline ADF & $-3.118(6)$ & $-3.424(6)$ & $-5.553(6)$ & $-5.354(6)$ & $-5.194(6)$ & $-5.769(6)$ & $-6.093(6)$ \\
PP & $-197.121(5)$ & $-188.95(5)$ & $-284.73(5)$ & $-263.9(5)$ & $-276.43(5)$ & $-241.1(5)$ & $-261.33(5)$ \\
\hline
\end{tabular}

Notes:

1. The restrictions for the ADF and PP tests in levels are the constant and trend.

2. Both the critical values for the ADF and PP tests are -3.43 at the $1 \%$ level, and all the test statistics reject the null hypothesis at the $1 \%$ level.

3. The number in parenthesis is the lag length.

\section{Empirical Results}




\subsection{Multivariate Granger Causality Test}

Table 3 reports the multivariate Granger causality test results. In general, there are no spillover effects from RMB ordinary shares (SHAI and SZAI) to exchange rate changes. It can be expressed as $\mathrm{SR}_{\mathrm{A}} \nRightarrow \mathrm{ER}$, where the subscript $A$ denotes RMB ordinary shares. The shocks from the volatile returns of foreign capital share listed in the Shenzhen market have significant impact on the returns of Shanghai B shares, that is $S R_{S Z B I} \Rightarrow S R_{S H B I}$. The returns of Shenzhen A-Share index show obvious effects on the returns of Shenzhen B shares. Both foreign exchange rate changes exhibit spillover effects on the Hong Kong stock market, $E R \Rightarrow S R_{H S I}$. Interestingly, the changes in HKD/RMB show significant impact on the returns of USD/RMB. This could be explained that the Hong Kong market is more volatile and easy-floating compared to the mainland market. Another reason is that the Hong Kong government adopts a linked-USD currency policy. The evidence is different from the existing flow-oriented exchange rate theory, which could be due to the effect of different monetary policies, as it is an important factor affecting the expectation and participation of stock market (Hung and Ma, 2017).

The findings from the multivariate VAR test are generally consistent with the Chinese currency policy. Exchange rate changes cannot affect stock returns in the Chinese financial market due to the implementation of a managed floating exchange rate policy, but foreign capital share returns have significant effects on exchange rates, which is in accordance with the classical "stock-oriented" economic theory. Since the Hong Kong government implements a linked exchange rate system, the HKD is mainly pegged to the USD. This could be used to interpret why changes in USD/RMB can Granger-cause the fluctuation of HKD/RMB. 
Table 3: Multivariate granger causality test

(Sample period: 01/1994-01/2018)

\begin{tabular}{cccccccc}
\hline & SHAI & SHBI & SZAI & SZBI & HSI & USD/RMB & KD/RMB \\
\hline SHAI & & 0.05 & 0.04 & 2.20 & 2.16 & 0.00 & 0.12 \\
SHBI & 0.06 & & 0.14 & 2.06 & 0.62 & 0.13 & 0.12 \\
SZAI & 0.31 & 0.11 & & $3.55^{*}$ & 1.43 & 0.02 & 0.38 \\
SZBI & 2.35 & $12.76^{* * *}$ & 1.06 & & 1.05 & 0.65 & 0.21 \\
HIS & 1.00 & 1.21 & 0.68 & 0.07 & & 0.31 & 0.03 \\
USD/RMB & 0.01 & 1.00 & 0.06 & 1.18 & $4.19^{* *}$ & & 0.01 \\
HKD/RMB & 0.06 & 0.87 & 0.24 & 1.39 & $4.56^{* *}$ & $4.69^{* *}$ & \\
\hline
\end{tabular}

Notes:

1. The Granger causality test is to test the coefficient of lagged parameters applying the Wald test.

2. *,**,*** indicate the significance levels at $10 \%, 5 \%$ and $1 \%$, respectively.

\subsection{A Parsimonious Conventional SVAR Analysis}

The multivariate Granger causality test just gives a broad picture on the linkages between the stock market and the exchange rate market in China. It provides little evidence on the spillover effects. Thurs, we estimate a SVAR model to observe the contemporaneous effects between exchange rate changes and stock returns. The most controversial part of the SVAR approach is the imposing of restrictions on the variance-covariance matrix. A triangular Cholesky decomposition which restricts the elements above the diagonal matrix as zero just identifies the model. However, which parameters should be imposed as zero? This can be really counterintuitive. Following Sims (1986), this study derives the restrictions based on theory assumptions and practical experiences. According to equation (4) and its derivatives on the structural shocks, the restrictions on the SVAR are given in equation (12). 


$$
\left[\begin{array}{ccccccc}
1 & \mathrm{a}_{12} & \mathrm{a}_{13} & \mathrm{a}_{14} & \mathrm{a}_{15} & \mathrm{a}_{16} & \mathrm{a}_{17} \\
\mathrm{a}_{21} & 1 & 0 & \mathrm{a}_{24} & \mathrm{a}_{25} & \mathrm{a}_{26} & 0 \\
0 & 0 & 1 & 0 & \mathrm{a}_{35} & \mathrm{a}_{36} & 0 \\
\mathrm{a}_{41} & 0 & \mathrm{a}_{43} & 1 & 0 & \mathrm{a}_{46} & \mathrm{a}_{47} \\
0 & 0 & 0 & \mathrm{a}_{54} & 1 & \mathrm{a}_{56} & 0 \\
0 & \mathrm{a}_{62} & 0 & 0 & 0 & 1 & 0 \\
0 & 0 & 0 & \mathrm{a}_{74} & 0 & \mathrm{a}_{76} & 1
\end{array}\right]\left[\begin{array}{c}
\mathrm{u}_{\mathrm{t}}^{\text {SHAI }} \\
\mathrm{u}_{\mathrm{t}}^{\text {SHBI }} \\
\mathrm{u}_{\mathrm{t}}^{\text {SZAI }} \\
\mathrm{u}_{\mathrm{t}}^{\text {SZBI }} \\
\mathrm{u}_{\mathrm{t}}^{\mathrm{HSI}} \\
\mathrm{u}_{\mathrm{t}}^{\mathrm{USD} / \mathrm{RMB}} \\
\mathrm{u}_{\mathrm{t}}^{\text {HKD } / \mathrm{RMB}}
\end{array}\right]=\left[\begin{array}{c}
\varepsilon_{\mathrm{t}}^{\text {SHAI }} \\
\varepsilon_{\mathrm{t}}^{\text {SHBI }} \\
\varepsilon_{\mathrm{t}}^{\text {SZAI }} \\
\varepsilon_{\mathrm{t}}^{\text {SZBI }} \\
\varepsilon_{\mathrm{t}}^{\mathrm{HSI}} \\
\varepsilon_{\mathrm{t}}^{\mathrm{USD} / \mathrm{RMB}} \\
\varepsilon_{\mathrm{t}}^{\text {HKD } / \mathrm{RMB}}
\end{array}\right]
$$

The first equation indicates that the SHAI responds to the shocks from other stock markets (SHBI, SZAI and HSI) and the foreign exchange market (USD/RMB). Since the Shanghai stock market is more sensitive to external shocks, this study assumes that these variables have contemporaneous effects on the SHAI. The zero restrictions designate that there are no structural innovations from other markets. Similarly, the restrictions on other equations could be derived in the same manner. Lag length selection for the conventional SVAR model is determined by the information criterion. We use the same lag length as selected in the multivariate Granger causality test. The restrictions on short run parameters might overidentify the SVAR model. In this case, the likelihood ratio (LR) test cannot completely reject the null hypothesis. The $\chi^{2}$ statistic equals 4.7 with a p-value of 0.095 , which partially accept the null hypothesis. ${ }^{8}$ This implies that the short run restrictions in equation (12) are just partly valid. These restrictions are derived based on subjective speculations. Moreover, most impulse response functions (not reported) have a long duration with high parameter uncertainty in the estimated short run parameters. In conjunction with the overidentification test, the conventional SVAR estimates fail to interpret the contemporaneous effects between exchange rate changes and stock returns. While the MS-SVAR approach avoids this issue by selecting switching parts on the mean or variances according to the likelihood ratio test and information criteria. It has been a major improvement in identifying structural innovations with SVAR models.

\footnotetext{
${ }^{8}$ The null hypothesis of this test is that any overidentifying restrictions are valid.
} 


\subsection{Empirical Analysis from SVAR with Markov Switching in}

\section{Volatility}

\subsubsection{Model Selection and Prior Specifications}

The final state selection for MS models is 2 states, which meets the requirement of model stability and the reality in the Chinese financial market. Normally, the log likelihood statistic with Akaike Information Criteria(AIC) and Schwarz Criteria (SC) are reliable to determine the best MS model (Psaradakis and Spagnolo, 2006; Herwartz and Luetkepohl, 2011). The default prior specifications for SVAR are the six hyper-parameters proposed by Sims and Zha (2006). ${ }^{9}$ In the Markov switching process, each element of the diagonal matrix $\xi^{2}\left(s_{t}\right)$ is a gamma distribution prior and the parameters $(\alpha, \beta)$ are set as $\bar{\alpha}=1$ and $\bar{\beta}=1$ in $\operatorname{Gamma}(\alpha, \beta)$ (Sims et al., 2008). The prior on the transition matrix $Q$ is a Dirichlet distribution, which have unrestricted parameters $\alpha_{i, j}$ and restricted parameters $\beta_{\mathrm{i}, \mathrm{j}}$. In the transition matrix $Q$, all the off-diagonal elements are set as one and the diagonal elements are computed by $\alpha_{i, j}=\frac{p_{j, d u r(h-1)}}{1-p_{j, d u r}}$, where $p_{j, d u r}$ is the average duration of the Markov Chain.

Figure 2: Smoothed State Probabilities (High regime)

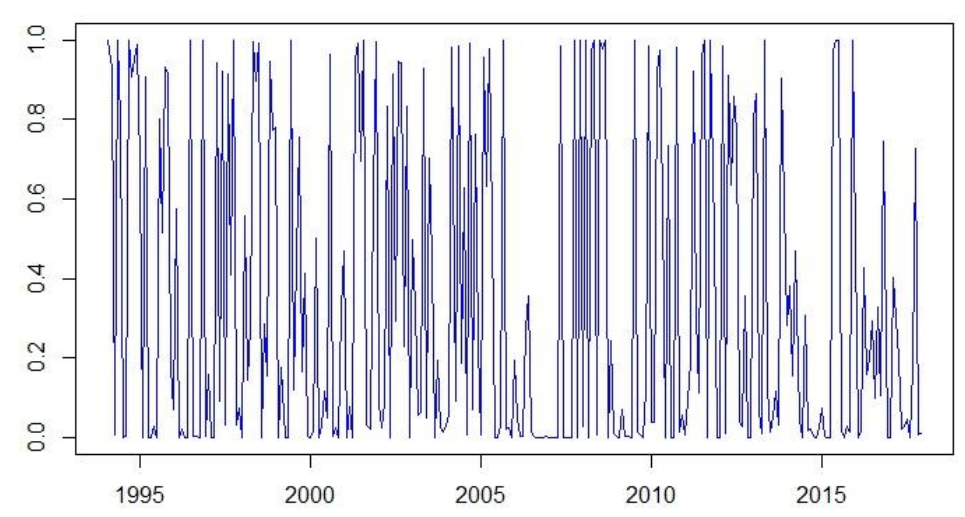

Figure 3: Smoothed State Probabilities (Low regime)

\footnotetext{
${ }^{9}$ Following Sims and Zha (2006), the prior specifications in this study are $\mu 1=0.57, \mu 2=0.13, \mu 3$ $=0.1, \mu 4=1.2, \mu 5=10$ and $\mu 6=10$.
} 


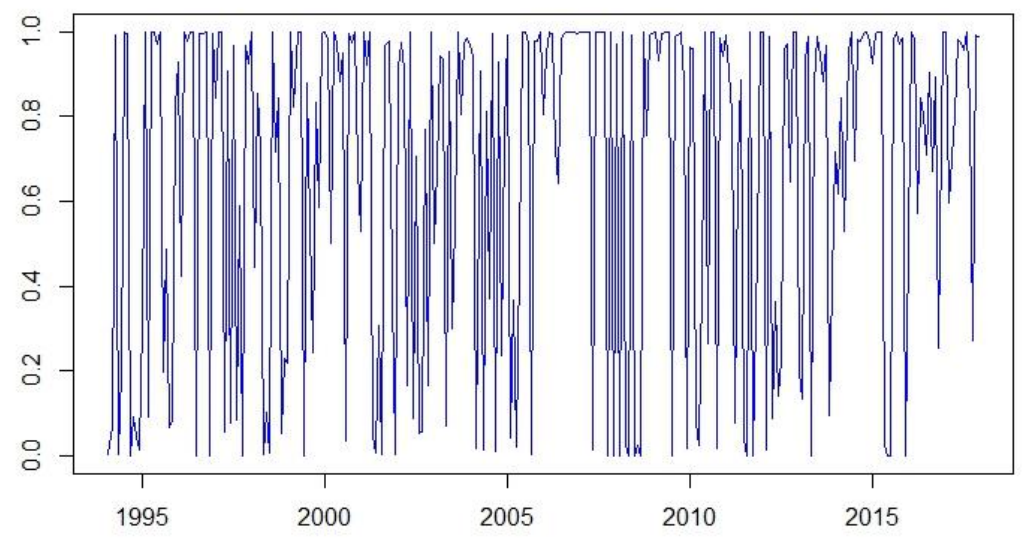

In the MS-SVAR model, the volatility structure is demonstrated in the Markov chain with transition probabilities. The model restrictions are just the switching parts in the mean or variances. Any other restrictions will be unnecessary. Figures 2-3 represent smoothed state probabilities for the monthly data sample ranging from 1994 to 2018. The MS-SVAR model has two different switching states, which are referred to as distressed state and normal (tranquil) state. The probabilities to remain at the low and high state has a higher probability in maintaining on its ongoing state, but the probabilities for the low regime are higher than the probabilities for the high regime. The evidence demonstrate that the low volatility regime tend to be more persistent than the high volatility regime, which is consistent with the findings from Papadamou and Markopoulos (2018). The high state roughly corresponds to the periods of the 1997 Asian financial crisis and the 2008 global financial crisis. Volatile markets also appear around 2005 which demonstrate the bull market period in the Chinese financial market.

Figure 4: Posterior densities of Markov switching intercepts 


\section{Intercept densities by regime}
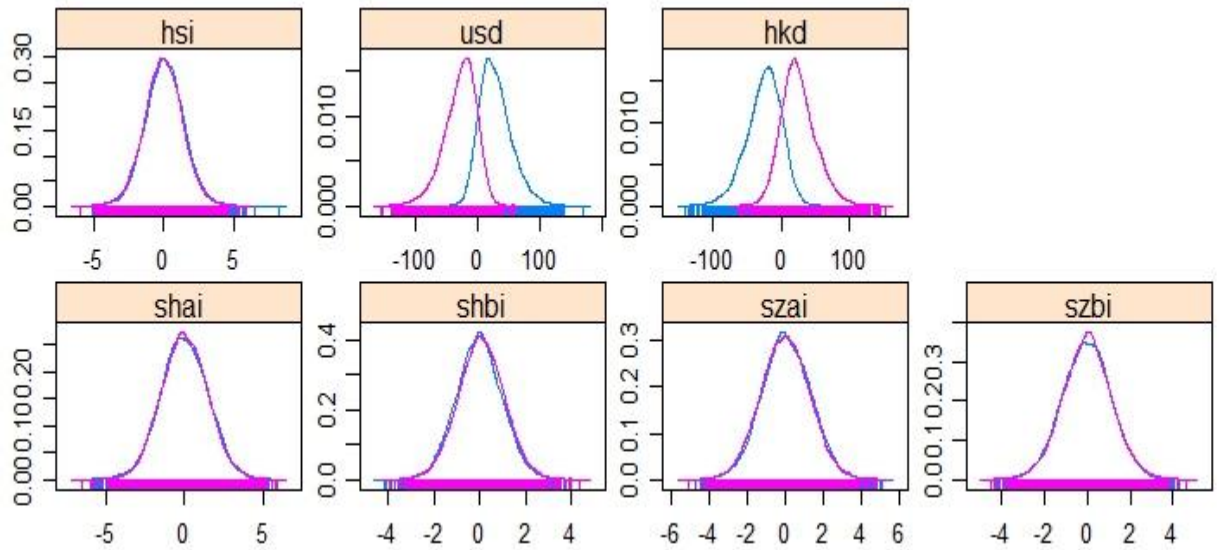

For the Markov switching model, the regime identification could be represented by posterior densities. Figure $\mathbf{4}$ shows the approximated posterior densities of parameters ( SHAI,SHBI,SZAI,SZBI,HSI,USD and HKD). Most of the endogenous variables exhibit a concentrated intercept switching near the zero bound. This indicates that there is evidence of overlap with the posterior densities in the two regimes. However, intercepts for exchange rates(USD and HKD) are not concentrated around the zero bound. It means that there is no overlap with the posterior densities. This seems to suggest that foreign exchange markets tend to have level effects on the domestic stock markets.

Figure 5: Posterior densities of Markov switching variances
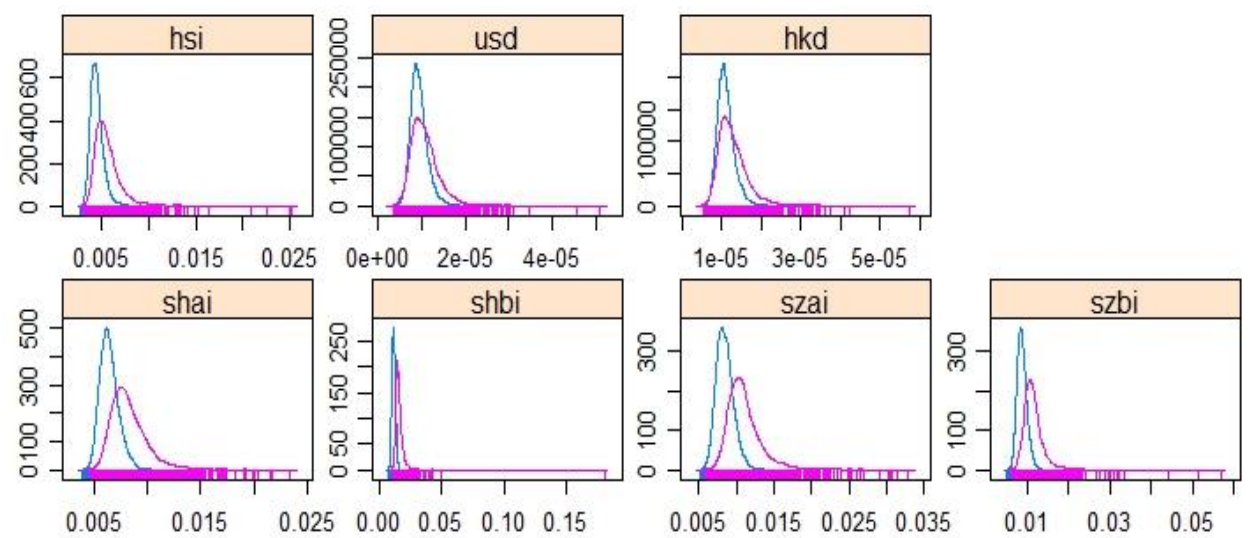
Figure 5 shows the kernel estimate of posterior densities of Markov switching variances. Although the posterior density of intercept switching does not present any evidence of interconnection in the stock market, the variance-switching show significant spillover effects in the Chinese financial market, as indicated in the non-overlap densities. Figure 6 gives the plots of transition densities by regime. There is a high probability for the state maintaining its ongoing state. The probabilities to remain at the regime 1 are from 0.71 to 0.79 and to regime 2 are from 0.7 to 0.8 in the peak, respectively. However, it is worth noticing that the transition between the two regimes still shows a relatively high probability, i.e. 0.2 to 0.3 in the transition densities. This means that the Chinese financial market is vulnerable and cannot resist to external shocks. The spillovers have longer durations during financial crisis periods. This might be due to the restriction on currency daily trading band in China. In the short run, exchange rate shocks have limited influence on stock returns in China. In the long run, the Chinese government keeps the RMB from instability by means of capital control, setting the RMB daily central parity rate, buying or selling USD in the foreign exchange market, etc. The results on the spillover effects between exchange rates and stock prices in the Chinese financial market presented in this study is consistent with the currency policy in China.

Figure 6: Transition densities by regime
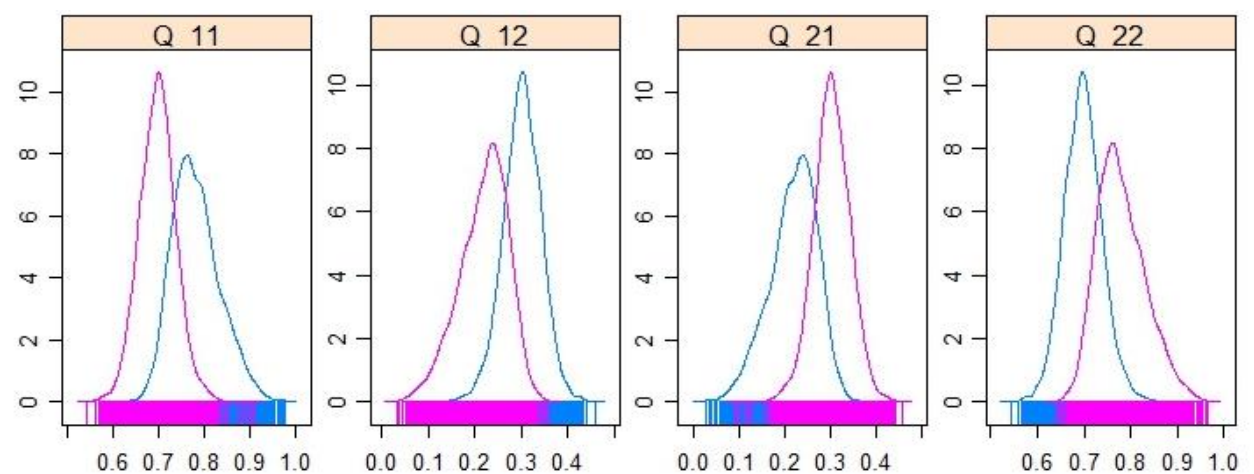

Looking inside the realities of the Chinese financial market, any shocks from the foreign exchange market could be limited in the short run, since the managed floating exchange rate system 
has restrictions on the RMB daily trading band. Even the shock continues, investors might have adjusted to the adverse shock. Thus, exchange rate changes exhibit no spillovers on stock returns. This is due to the implementation of a managed floating exchange rate policy in China. As the Chinese financial market is far more than mature, the authorities have to insist on the current exchange rate policy in order to protect the vulnerable Chinese financial market against external shocks. The Hong Kong market has seen an increasing connection with the mainland stock market since the return of Hong Kong. However, with the relaxing of restrictions on the RMB, the shock from currency movements appears to be significant as demonstrated by the estimated densities of variance-switching. Looking to the future, the authorities are trying to internationalise the RMB, this might bring systematic risks to the Chinese financial market and alter the current unidirectional relationship between exchange rate changes and stock returns.

\section{Concluding Remarks}

This study has explored the correlation between exchange rate changes and stock returns in the Chinese financial market. The multivariate Granger causality test suggests that there is no long run correlation between stock markets and foreign exchange markets. Foreign capital shares listed in the Shanghai market tend to have spillover effects on the returns of Shenzhen B shares. Changes in the USD show significant impact on the Hong Kong foreign exchange market. The evidence gives a clear message that there are no interconnections between stock returns and currency movements at levels. However, spillover effects exist in the Chinese financial markets, in particular the volatility from the foreign exchange market.

As for practical implications, investors could make appropriate adjustments referring to the fluctuations of the SHBI. The shocks from the Hong Kong stock market are also potential risks to their investment returns since the linkages between the Hong Kong stock market and the mainland 
stock market are ever increasing. Although exchange rate movements only exhibit contemporaneous spillovers on stock returns, investors need to pay attention to the RMB policy changes, since the daily RMB trading band is gradually loosening and the speed of the RMB internationalization is accelerating. This could bring systematic risks to the Chinese financial market and change the current causal relationship. Since the Chinese financial market is far more than mature, the authorities have to insist on the current exchange rate policy in order to protect the vulnerable Chinese financial market against external shocks. In the short run, exchange rate shocks have limited influence on stock returns in China. In the long run, the Chinese government keeps the RMB from instability by means of capital control, setting the RMB daily central parity rate, buying or selling USD in the foreign exchange market, etc.

For the area of future research, one innovative work might be the application of asymmetry models into time series analysis, such as asymmetric spillover effects in financial markets and asymmetric exchange rate exposure. Another avenue for further research could be the improvement of existing time series models, for instance, developing the nonlinear data generating process to restructure the existing unit root test. Finally, possible extension of personal research interests could be the application of panel data approaches into multinational samples, as well as the analysis on future reforms and influences of the RMB exchange rate using dynamic stochastic general equilibrium models.

\section{References}

Bahmani-Oskooee, M. and A. Sohrabian (1992). Stock prices and the effective exchange rate of the dollar. Applied Economics 24 (4), 459-464.

Bailey, W. (1994). Risk and return on China's new stock markets: Some preliminary evidence. Pacific-Basin Finance Journal 2 (2), 243-260. 
Boako,G. and Alagidede, P.(2017). Currency price risk and stock market returns in Africa: Dependence and downside spillover effects with stochastic copulas, Journal of Multinational Financial Management, 41, 92-114.

Caporale G.M., Ali F.M., Spagnolo. F. and Spagnolo N.(2017) International portfolio flows and exchange rate volatility in emerging Asian markets. Journal of International Money and Finance, (76), 1-15.

Chkili, W. and D. K. Nguyen (2013). Exchange rate movements and stock mar-ket returns in a regime-switching environment: Evidence for BRICS countries. Research in International Business and Finance.

Choi, J. J., E. Elyasiani, and K. J. Kopecky (1992). The sensitivity of bank stock returns to market, interest and exchange rate risks. Journal of Banking \& Finance 16 (5), 983-1004.

Chow, G. C., Z.-z. Fan, and J.-y. Hu (1999). Shanghai stock prices as determined by the presentvalue model. Journal of Comparative Economics 27 (3), 553-561.

Chow, G. C., C. Liu, and L. Niu (2011). Co-movements of shanghai and new york stock prices by time-varying regressions. Journal of Comparative Eco-nomics 39 (4), 577-583.

Coudert, V., C. Couharde, and V. Mignon (2011). Exchange rate volatility across financial crises. Journal of Banking \& Finance 35 (11), 3010-3018.

Cuestas, J. C., Huang, Y. S., \& Tang, B. (2018). Does internationalisation increase exchange rate exposure? -evidence from chinese financial firms. International Review of Financial Analysis, 56, 253-263.

Davig, T. and C. Hakkio (2010). What is the effect of financial stress on economic activity. Economic Review (Q II), 35-62.

Dickey, D. A. and W. A. Fuller (1979). Distribution of the estimators for autoregressive time series with a unit root. Journal of the American Statistical Association 74 (366a), 427-431.

Dominguez, Kathryn M.E.and Tesar, L. L. (2001). A Re-examination of Exchange Rate Exposure. The American Economic Review 91 (2), 396-399.

Doornick, J. and H. Hansen (1994). A practical test for univariate and multivariate normality. Technical report, Discussion Paper, Nuffield College. 
Dornbusch, R. and S. Fischer (1980). Exchange rates and the current account. American Economic Review 70 (5), 960-71.

Enders A. Enders Z. and Hoffmann M. (2018) International financial market integration, asset compositions, and the falling exchange rate pass-through. Journal of International Economics, (110),151-175.

Fang, W. (2002). The effects of currency depreciation on stock returns: Evidence from five East Asian economies. Applied Economics Letters 9 (3), 195-199.

Frankel, J. A. (1983). Monetary and Portfolio-Balance Models of Exchange Rate Determination. Technical report, National Bureau of Economic Research.

Gavin, M. (1989). The stock market and exchange rate dynamics. Journal of International Money and Finance 8 (2), 181-200.

Grammig, J., M. Melvin, and C. Schlag (2005). Internationally cross-listed stock prices during overlapping trading hours: price discovery and exchange rate effects. Journal of Empirical Finance 12 (1), 139-164.

Granger, C. W., B.-N. Huangb, and C.-W. Yang (2000). A bivariate causality between stock prices and exchange rates: evidence from recent Asian flu. The Quarterly Review of Economics and Finance 40 (3), 337-354.

Griffin, J. M. and R. M. Stulz (2001). International competition and exchange rate shocks: a crosscountry industry analysis of stock returns. Review of Financial Studies 14 (1), 215-241.

Hung K. and Ma T.(2017) Does monetary policy have any relationship with the expectations of stock market participants?. Journal of Multinational Financial Management, (39),100-117.

Jarque, C. M. and A. K. Bera (1987). A test for normality of observations and regres-sion residuals. International Statistical Review/Revue Internationale de Statistique, 163-172.

Johansson, A. C. and C. Ljungwall (2009). Spillover effects among the Greater China stock markets. World Development 37 (4), 839-851.

Kim, K.-h. (2003). Dollar exchange rate and stock price: evidence from multivariate cointegration and error correction model. Review of Financial Economics 12 (3), 301-313.

Kollias, C., Mylonidis, N., \& Paleologou, S. (2012). The nexus between exchange rates and stock markets: Evidence from the euro-dollar rate and composite European stock indices using rolling analysis. Journal of Economics and Finance, 36, 136-147. 
Kollias, C., Papadamou, S., \& Siriopoulos, C. (2016). Stock markets and effective exchange rates in European countries: threshold cointegration findings. Eurasian Economic Review, 6(2), 215-274.

Kumar, M. (2013). Returns and volatility spillover between stock prices and exchange rates: Empirical evidence from IBSA countries. International Journal of Emerging Markets, 8, 108-128.

Kutty, G. (2010). The relationship between exchange rates and stock prices: The case of Mexico. North American Journal of Finance and Banking Research, 4, 1-12.

Lanne, M., H. LÃijtkepohl, and K. Maciejowska (2010). Structural vector au-toregressions with Markov switching. Journal of Economic Dynamics and Con-trol 34 (2), 121 - 131.

Lanne, M. and H. Lütkepohl (2010). Structural vector autoregressions with nonnormal residuals. Journal of Business \& Economic Statistics 28 (1).

Li, Y., D. Yan, and J. Greco (2006). Market segmentation and price differentials between A shares and $\mathrm{H}$ shares in the Chinese stock markets. Journal of Multi-national Financial Management 16 (3), 232-248.

Lin, C.-H. (2012). The comovement between exchange rates and stock prices in the Asian emerging markets. International Review of Economics \& Finance 22 (1), 161-172.

L“utkepohl, H. (2005). New Introduction to Multiple Time Series Analysis. Springer.

Ma, C. K. and G. W. Kao (1990). On exchange rate changes and stock price reactions. Journal of Business Finance \& Accounting 17 (3), 441-449.

Ma, G. and R. N. McCauley (2011). The evolving Renminbi regime and implications for Asian currency stability. Journal of the Japanese and International Economies 25 (1), 23-38.

Mehrotra, A. N. (2007). Exchange and interest rate channels during a deflationary era-Evidence from Japan, Hong Kong and China. Journal of Comparative Economics 35 (1), 188-210.

Netsunajev, A. (2013). Reaction to technology shocks in Markov-switching structural VARs: Identification via heteroskedasticity. Journal of Macroeconomics.

Nieh, C.-C. and C.-F. Lee (2002). Dynamic relationship between stock prices and exchange rates for G-7 countries. The Quarterly Review of Economics and Fi-nance 41 (4), 477-490.

Nieh, C.-C. and H.-Y. Yau (2010). The impact of Renminbi appreciation on stock prices in China. Emerging Markets Finance and Trade 46 (1), 16-26. 
Pan, M.-S., R. C.-W. Fok, and Y. A. Liu (2007). Dynamic linkages between exchange rates and stock prices: Evidence from East Asian markets. International Review of Economics \& Finance 16 (4), 503-520.

Papadamou, S., \& Markopoulos, T. (2018). Interest rate pass through in a Markov-switching Vector Autoregression model: Evidence from Greek retail bank interest rates. The Journal of Economic Asymmetries, 17, 48-60.

Phillips, P. C. and P. Perron (1988). Testing for a unit root in time series regression. Biometrika 75 (2), 335-346.

Phylaktis, K. and F. Ravazzolo (2005). Stock prices and exchange rate dynamics. Journal of International Money and Finance 24 (7), 1031-1053.

Poon, W. P. and H.-G. Fung (2000). Red chips or H shares: which China-backed securities process information the fastest? Journal of Multinational Financial Management 10 (3), 315-343.

Psaradakis, Z. and N. Spagnolo (2006). Joint determination of the state dimension and autoregressive order for models with Markov regime switching. Journal of Time Series Analysis 27 (5), 753-766.

Rjoub, H. (2012). Stock prices and exchange rates dynamics: Evidence from emerg-ing markets. African Journal of Business Management 6 (13), 4728-4733.

Sensoy, A., \& Tabak, B. M. (2016). Dynamic efficiency of stock markets and exchange rates. International Review of Financial Analysis, 47, 353-371.

Sims, C. A. (1986). Are forecasting models usable for policy analysis? Federal Reserve Bank of Minneapolis Quarterly Review 10 (1), 2-16.

Sims, C. A., D. F. Waggoner, and T. Zha (2008). Methods for inference in large multiple-equation Markov-switching models. Journal of Econometrics 146 (2), 255-274.

Sims, C. A. and T. Zha (2006). Were there regime switches in US monetary policy? The American Economic Review, 54-81.

Tabak, B. M. (2006). The dynamic relationship between stock prices and exchange rates: Evidence for Brazil. International Journal of Theoretical and Applied Finance 9 (08), 1377-1396.

Tovar-Silos, R. and F. Shamim (2013). The Empirical Relationship between Ex-change Rates and Stock Market Returns in South Africa: A Markov Regime-Switching Approach. International Research Journal of Applied Finance 4 (12), 1540-1553. 
Wang K.M. and Lee Y.M.(2016) Hedging exchange rate risk in the gold market: A panel data analysis. Journal of Multinational Financial Management, (35), 1-23.

Walid, C., A. Chaker, O. Masood, and J. Fry (2011). Stock market volatility and ex-change rates in emerging countries: A Markov-state switching approach. Emerging Markets Review 12 (3), 272 292.

Woo, W. T. (2008). Understanding the Sources of Friction in US-China Trade Rela-tions: The Exchange Rate Debate Diverts Attention from Optimum Adjustment. Asian Economic Papers 7 (3), 61-95.

Zhao, H. (2010). Dynamic relationship between exchange rate and stock price: Evidence from China. Research in International Business and Finance 24 (2), 103-112. 